\title{
Retrospective Evaluation of Sixty Five Year and Older Patients with Metastatic Colorectal Cancer
}

\section{Altmışbeş Yaş ve Üzeri Metastatik Kolorektal Kanserli Hastaların Retrospektif Değerlendirilmesi}

\author{
Havva Yeşil Çınkır ${ }^{1}$, Berna Öksüzoğlu \\ ${ }^{1}$ Gaziantep Üniversitesi Tıp Fakültesi, Tıbbi Onkoloji, Gaziantep, Türkiye \\ ${ }^{2}$ Dr. Abdurrahman Yurtaslan Ankara Onkoloji Eğitim ve Araştırma Hastanesi, Tıbbi Onkoloji, Ankara, Türkiye
}

Dergiye Ulaşma Tarihi: 21.09.2018 Dergiye Kabul Tarihi: 26.08.2019 Doi: 10.5505/aot.2019.57441

\section{ÖZET}

GíRiș ve AMAÇ: Bu çalışma, 65 yaș ve üzerinde metastatik kolorektal kanser (KRK) tanısı alan hastaların genel özelliklerini, performans durumunu, uygulanan tedavileri ve sağ kalım oranlarının değerlendirilmesi amacı ile planlandi.

YÖNTEM ve GEREÇLER: Bu çalışma Ekim 2010 ile Ekim 2014 tarihleri arasında Dr. A.Y. Ankara Onkoloji Eğitim ve Araştırma Hastanesi Tıbbi Onkoloji Kliniği’nde metastatik evrede 65 yaş ve üzerinde olan KRK tanılı 139 hastanın dosya arşivi taranarak retrospektif olarak yapıldı.

BULGULAR: Hastaların ortanca yaşı 73 (65-87) idi. Yaş aralığına göre değerlendirildiğinde hastaların 81 ' i (\% 58,3) 65-74 yaş arasında, 53' ü $(\% 38,1) 75-84$ yaş arasında, 5’ i $(\% 3,6) 85$ yaș ve üzerinde idi. Çoğunluğunu erkek (\% 57) cinsiyet oluşturmaktaydı. Tüm hasta grubu için genel sağkalım (GSK) 12.09 ay (\% 95 GA; 9.514.64) idi. Yaş aralığına göre ortanca GSK 65-74 yaş arası 16.39 ay (\% $95 \mathrm{GA} ; 10.3-22.4), 75$ yaş ve üzeri 12.87 ay (\% $95 \mathrm{GA} ; 9.2-16.5$ ) (p: 0.906) idi.

TARTIŞMA ve SONUÇ: Kronolojik yaş tedavi planlamasında negatif bir faktör olarak düşünülmemelidir. Tanı ve evreleme sonrasında hastanın kişisel istekleri de gözönüne alınarak multidisipliner yaklaşım ile tedavi seçenekleri uygulanmalıdır. Karşılaşılabilecek toksisiteler için yakın ve dikkatli takip yapılmalı, gerekli durumlarda destek tedaviler uygulanmalıdır

Anahtar Kelimeler: Kolorektal kanser, metastaz

\begin{abstract}
INTRODUCTION: This study was planned with the aim of assessing general characteristics, performance status, applied treatments and survival rates of patients diagnosed with metastatic colorectal cancer (CRC) over the age of 65 years.

METHODS: This study was conducted between October 2010 and October 2014 at Dr. A.Y. Ankara Oncology Training and Research Hospital, Department of Medical Oncology Clinic. The files in the archives were scanned retrospectively and 139 patients diagnosed with colorectal cancer, who were 65 years or older in the metastatic stage were identified.

RESULTS: The median age of the patients was 73 (65-87). When evaluated according to age range, $81(58.3 \%)$ of the patients were aged between $65-74,53(38.1 \%)$ were between $75-84$ years and $5(3.6 \%)$ were over 85 years old. The majority $(57 \%)$ were male.

Overall survival was 12.09 months (\% $95 \mathrm{GA} ; 9.5-14.64)$. According to age range, median OS was 16.39 months between 65-74 years, 12.87 months (\% 95 GA; 9.2-16.5) (p: 0.906) over 75 years.

DISCUSSION and CONCLUSION: Advanced age should not be considered as a negative factor in planning treatment. After diagnosis and staging, multidisciplinary approach and treatment options should be applied considering personal wishes of the patient. Close and careful follow-up should be performed for toxicities that may be encountered, and supportive care should be applied when necessary.
\end{abstract}

Keywords: Colorectal cancer, metastasis, elderly 


\section{GíRiş}

Günümüzde gelişmiş ve gelişmekte olan ülkelerde genel nüfus içindeki yaşlı insan sayısı hızla artmaktadır. Bu durumda koruyucu ve tedavi edici tıp alanındaki ilerlemeler ile beslenme ve hayat şartlarındaki iyileştirmelerin etkisi büyüktür. Buna paralel olarak ortalama yaşam beklentisinin artmas1 ile 65 yaş üstü grubun tüm nüfusa oranı giderek artmaktadır (1).

İlerleyen yaş kanser gelişiminin en önemli risk faktörlerinden biridir. Tüm kanser vakalarının \% 50'si 65 yaş üzerinde görülmekte ve 65 yaş üzeri ölüm nedenleri arasında kansere bağlı ölümler kardiyak nedenlerden sonra ikinci sirada yer almaktadır (1).

Yaş faktörü tedavi kararı verilmesinde genellikle ayırt edici bir faktördür. Yaşlı hastalar çoğu kez, sadece yaşları nedeni ile genç hastalar gibi kılavuzlar doğrultusunda ve yeterli tedavi edilmemektedir. Yaşlı hastalarda kanser tedavisi planlanırken her bireyin işlevsellik düzeyi ve sahip olduğu rezerv iyi değerlendirilmelidir. Organ sistemlerinde meydana gelen fizyolojik değişiklikler sonucu oluşan yaşlanma ile hastalıklara bağlı bulgular birbirinden ayrılmalıdır. Birden fazla yandaş hastalığ1 ve kırılganlığ 1 olan yaşlı hastalarda tedavi modifikasyonu yapılsa da genellikle yaşlı hastalar için de genç bireyler için belirlenen genel tedavi prensipleri geçerlidir.

$\mathrm{Bu}$ çalışma, 65 yaş ve üzerinde metastatik kolorektal kanser (KRK) tanisı alan hastaların genel özelliklerini, performans durumunu, uygulanan tedavileri ve sağ kalım oranlarının değerlendirilmesi amacı ile planlandı.

\section{GEREÇ ve YÖNTEM}

Bu çalışma Ekim 2010 ile Ekim 2014 tarihleri arasında Dr. A.Y. Ankara Onkoloji Eğitim ve Araştırma Hastanesi Tibbi Onkoloji Kliniği takibine girmiş veya bu klinikte tanı almış hastaların dosya arşivi taranarak retrospektif olarak yapıld1. Çalışma için yerel izinler ve etik kurul onayı alındı. Çalışmaya dosya verileri kullanılabilir, metastatik evrede 65 yaş ve üzerinde olan KRK'li hastalar dahil edildi. Hastaların yaşları, cinsiyeti, performans durumu, tanı tarihi, tümörün yerleşim yeri, histolojisi, evresi, opere olmuş ise operasyon tarihi, metastaz yerleri, RAS durumu, metastazektomi yapılmış ise yeri ve tarihi, metastatik evrede aldığ 1 tedaviler, yan etkiler kaydedildi. Hastaların performans durumu değerlendirmesi Eastern Cooperative Oncology Group (ECOG) değerlendirmesi ile yapıld1. Hastaların evrelemesi TNM AJCC 2010 sinıflamasına göre kaydedildi. Tedavi ilişkili yan etkiler Common Terminology Criteria for Adverse Events (CTCAE) versiyon 4.0 'e göre değerlendirildi.

Veriler Statistical Package for Social Sciences (SPSS v15.0, SPSS Inc. Chicago, IL, USA) software paket programında analiz edildi. Tanımlayıcı analizlerde yüzde, ortanca, ortalama değerleri hesaplandı. Sağkalım süreleri ve gruplar arasındaki sağ kalım farkları Kaplan-Meier ve log rank analizi kullanılarak hesapland. İstatistiksel anlamlılık $\mathrm{p}$ değerinin $0.05^{\prime}$ den küçük olması olarak belirlendi.

\section{SONUÇLAR}

Kliniğimizde dosya numarası verilen 1444 KRK'li hastanın 512' si 65 yaş ve üzeri idi. Çalışmaya dosya verileri kullanılabilir, metastatik evrede 65 yaş ve üzerinde olan KRK tanılı 139 hasta dahil edildi. Hastaların metastatik evredeki ortanca yaşı 73 (65-87) idi. Yaş aralığına göre değerlendirildiğinde hastaların 81'i $(\%$ 58,3) 65-74 yaş arasında, 53 'ü $(\% 38,1) 75-84$ yaş arasında, 5'i $(\% 3,6)$ 85 yaş ve üzerinde idi. Hastaların çoğunluğunu erkek (\%57) cinsiyet oluşturmaktayd1, erkek/kadın oranı: 1,3 olarak hesaplandı. Tablo 1 'de hastaların klinik ve demografik özellikleri gösterilmektedir.

Hastaların 102' si $(\% 73,3)$ tanı anında metastatik evrede idi. Bu hastaların 62' si evre 4A, 40' 1 evre 4B idi. 37 hasta tanı anında erken evre olup takiplerinde metastatik evrede 65 yaş ve üzerindeydi. Tablo 2'de metastatik KRK'li hastaların tümör özellikleri gösterilmektedir. Tümör lokalizasyonu en s1k rektum (\%46) idi. Histolojik alt tip en s1k adenokarsinom idi.

Hastaların kolorektal bölgedeki primer lezyonun operasyon şekline göre; $47(\% 33,8)$ hastaya palyatif, $45(\% 32,4)$ hastaya küratif amaçla operasyon uygulanmıştı, $47(\% 33,8)$ hastaya operasyon yapılmamıştı. Primer lezyonu opere edilen hastalarda operasyon için en sık neden obstrüksiyon bulguları idi. Hastaların \%13,6' sina metastazektomi 
uygulanmıştı. On yedi hastaya $1 \mathrm{kez}, 1$ hastaya $2 \mathrm{kez}$ ve 1 hastaya da $3 \mathrm{kez}$ uygulanmıştı. En sık metastazektomi yeri \%89 oranında karaciğerdi.

34 hasta herhangi bir tedavi almadi. Tedavi alamamalarının nedenleri; performans düşüklüğü, yandaş hastalıklar ve hasta yakınlarının tedavi istememeleri idi. Metastatik evrede palyatif tedavi olarak 97 hasta bir sira, 34 hasta iki sıra, 11 hasta üç sıra kemoterapi ald1. Metastazektomi sonras1 19 hastaya kemoterapi uygulandı. Hastaların aldığı kemoterapi protokollerine göre değerlendirildiğinde (Tablo 3) en s1k olarak okzaliplatin içeren (kapesitabin-okzaliplatin, mFOLFOX6) tedaviler başlandı. Birinci sıra tedavide en s1k kapesitabin-okzaliplatin, ikinci sira tedavide FOLFIRI-bevasizumab, üçüncü sira tedavide FOLFIRI-bevasizumab tercih edilmişti.

Takip sirasında 48 (\%34.5) hastada tedavi ilișkili yan etki gözlendi. Tüm derecelerde yan etkiler sirasiyla; halsizlik 40 (\%28.7), anemi 42 (\%30.2), lökopeni 38 (\%27.3), bulant1-kusma 35 (\%25.1), mukozit 30 (\%21.5), diyare 20 (\%14.3), trombositopeni 20 (\%14.3), febril nötropeni $7(\% 5)$, akut böbrek yetmezliği 1, periperik nöropati 15 (\%10.7) ve derin ven trombozu 2 hastada gözlendi. En sik 3-4. derece hematolojik yan etki olarak lökopeni 12 (\%8.6), anemi 7 (\%5) ve trombositopeni 28 (\%1.4) hastada; nonhematolojik yan etki olarak diyare $6(\% 4,3)$, mukozit 5 (\%3.5) ve halsizlik 2 (\%1.4) hastada gözlendi. 38 (\% 27.3) hastaya kemoterapi doz redüksiyonu uygulandı. Hiçbir hastada yan etkiye bağlı ölüm saptanmadı.

Ortanca takip süresi tüm grup için 11 ay (1-108) olarak bulundu. Bu takip süresinde toplamda $91 \quad(\% \quad 65,5)$ hastanın öldüğü saptand1. 59 kadın hastanın 39' u, 80 erkek hastanın 52' si yaşamını yitirdi. Kaplan-Meier sağkalım analizinde tüm hasta grubu için median genel sağkalım (GSK) süresi 12.09 ay (\% 95 Güven aralığı (GA); 9.5-14.64; 0.3646.3 ay) idi. Tedavi alanlarda median GSK 19.25 ay (\% 95 GA; $13.9-24.5 ; 2.79-46.39)$, tedavi almayanlarda 3.3 ay (\%95 GA; 2.1-4.6 ay) idi.

Yaş aralığına göre ortanca GSK 65-74 yaş aras1 16.39 ay (\% 95 GA;10.3-22.4), 75 yaş ve üzeri 12.87 ay (\% $95 \mathrm{GA} ; 9.2-16.5)$ (p:0.906) idi (Şekil 1).
Yandaş hastalığı olanlarda ortanca GSK süresi 13.2 ay iken olmayanlarda 18.5 ay (p:0.703) idi.

Tümör lokalizasyonuna göre ortanca GSK süresi sağ kolon (çekum, çıkan kolon, hepatik fleksura, transvers kolon 2/3 proksimali) yerleşimli olanlarda 12.09 ay ( $\% 95$ GA; 8,4-15,7), sol kolonda (sigmoid kolon, inen kolon, splenik fleksura, transvers kolon distali, rektum) 16.39 ay (\%95 GA; 10,9-21,8) (p:0.944) idi. Metastazektomi operasyonu yapilanlarda ortanca GSK süresine ulaşılamad1, yapılmayanlarda ise 13.2 ay (\%95 GA; 8,28-18,1) (p:0.001) idi.

Tablo 1. Metastatik evrede 65 yaş ve üzerinde olan hastaların klinik ve demografik özellikleri

\begin{tabular}{|l|l|}
\hline Hasta Özellikleri & Sayı (\%) \\
\hline Ortanca Yaş & $73(65-87)$ \\
\hline Yaş aralığı & \\
\hline 65-74 yaş arası & $81(\% 58,3)$ \\
\hline $75-84$ yaş arası & $53(\% 38,1)$ \\
\hline 85 yaş ve üzeri & $5(\% 3,6)$ \\
\hline Cinsiyet & \\
\hline Kadın & $59(\% 42,4)$ \\
\hline Erkek & $80(\% 57,6)$ \\
\hline $\begin{array}{l}\text { Performans Statusu } \\
\text { ECOG) }\end{array}$ & \\
\hline PS 0-1 & $82(\% 59)$ \\
\hline PS 2 & $46(\% 33,1)$ \\
\hline PS 3 & $11(\% \quad 7,9)$ \\
\hline Yandaş hastalık & \\
\hline Tek & $49(\% 39.2)$ \\
\hline İki & $50(\% 35,9)$ \\
\hline Üç veya daha fazla & $5(\%)$ \\
\hline Yok & \\
\hline
\end{tabular}


Tablo 2. Metastatik Evrede 65 yaş ve üzerinde olan KRK'li hastaların tümör özellikleri

\begin{tabular}{|c|c|}
\hline Tümör Özellikleri & Sayı (\%) \\
\hline \multicolumn{2}{|l|}{ Tümör Yerleşim Yeri } \\
\hline Rektum & $64(\% 46)$ \\
\hline Sigmoid kolon & $37(\% 26)$ \\
\hline Çıkan Kolon & $15(\% 10)$ \\
\hline İnen Kolon & $11(\% 7,9)$ \\
\hline Transvers Kolon & $5(\% 3,6)$ \\
\hline Çekum & $7(\% 5)$ \\
\hline \multicolumn{2}{|l|}{ Histolojik Alt Tip } \\
\hline Adenokarsinom & $130(\% 93,5)$ \\
\hline Müsinöz & $8(\% 5,8)$ \\
\hline Taşlı Yüzük Hücreli & $1\left(\begin{array}{ll}\% & 0,7\end{array}\right)$ \\
\hline \multicolumn{2}{|l|}{ Histolojik Farklılaşma } \\
\hline İyi Derece Diferansiye & $13(\% 9,4)$ \\
\hline Orta Derece Diferansiye & $39(\% 28,1)$ \\
\hline Az-Kötü Derece Diferansiye & e $5(\% 3,6)$ \\
\hline Belirtilmemiş & $82(\% 59)$ \\
\hline \multicolumn{2}{|l|}{ Metastaz Yeri } \\
\hline Karaciğer & $114(\% 82)$ \\
\hline Akciğer & $40(\% 28)$ \\
\hline Periton & $24(\% 17)$ \\
\hline Kemik & $13(\% 9)$ \\
\hline Beyin & 1 \\
\hline \multicolumn{2}{|l|}{ Metastaz Bölge Sayısı } \\
\hline Tek Bölge & $79(\% 56)$ \\
\hline İki Bölge & $46(\% 33)$ \\
\hline Üç Bölge & $14(\% 10)$ \\
\hline \multicolumn{2}{|l|}{ Metastezektomi Durumu } \\
\hline Yapilan & $19(\% 13,6)$ \\
\hline Yapılmayan & $120(\% 86,4)$ \\
\hline \multicolumn{2}{|l|}{ RAS durumu } \\
\hline \multicolumn{2}{|l|}{ KRAS } \\
\hline Wild & $40(\% 28)$ \\
\hline Mutant & $42(\% 30)$ \\
\hline Belirtilmemiş & $57(\% 41)$ \\
\hline \multicolumn{2}{|l|}{ NRAS } \\
\hline Wild & $9(\% 6,5)$ \\
\hline Mutant & $1(\% 0,7)$ \\
\hline Belirtilmemiş & $129(\% 92,8)$ \\
\hline
\end{tabular}

Tablo 3. Hastaların metastatik evredeki kemoterapi uygulamaları

\begin{tabular}{|lc|}
\hline Hastaların aldığı tedaviler & Sayı (Yüzde oranı) \\
\hline 1. basamak tedaviler & \\
\hline Okzalipatin içeren & $48(\% 49,4)$ \\
İrinotekan içeren & $31(\% 31,9)$ \\
Bevasizumab ile kombine & $23(\% 23,7)$ \\
Setuksimab ile kombine & $14(\% 14,4)$ \\
Panitumumab ile kombine & $2(\% 2)$ \\
Aflibercept ile kombine & $1(\% 1)$ \\
2. basamak tedaviler & \\
\hline \multicolumn{2}{l}{ Bevasizumab ile kombine } \\
Setuksimumab ile kombine & $3(\% 38,2)$ \\
Ziv-aflibercept ile kombine & $2(\% 5,8)$ \\
3. basamak tedaviler & \\
\hline Bevasizumab ile kombine & $5(\% 45,4)$ \\
Setuksimab ile kombine & $3(\% 27,2)$ \\
\hline
\end{tabular}

\section{TARTIŞMA}

Yaşlı hasta psikolojik, sosyoekonomik, ailesel ve toplum sağlığ 1 açılarından farklı bir yaş grubudur. Yaşa bağlı hemen hemen tüm değişiklikler fonksiyonel kayıplara yol açar. Fakat yaşlı nüfusun fonksiyonel bozulma oranı hem bireyler içinde hem de bireyler arasında belirgin bir değişkenlik gösterir (2). Son yıllarda tanı ve tedavide olan gelişmelere rağmen kolorektal kanser önemli sağlik sorunudur. KRK' li vakaların \% 70'i altmışbeş yaş ve üzerinde görülmektedir. Metastatik KRK'de tedavinin amac1 semptomlarin palyasyonu, yaşam kalitesinin artırılması ve yaşam süresinin iyileştirilmesidir. Geçmiş y1llarda anti-metabolit olan 5-fluorourasil ile yaşam süresi 12 aylar civarında iken yeni kemoterapötik ajanlar, cerrahi uygulamalar ve hedef biyolojik ajanların geliştirilmesi ile metastatik KRK' li hastaların tedavisinde başarı oranları artmıştır.

Evre 4B kolon kanseri tanılı 65 yaş üzeri 64 hastanın dahil edildiği çalışmada primer tümör rezeksiyonu yapılan grupta median GSK 12.43 ay iken opere edilmeyen grupta ise 3.58 ay olarak saptanmıştır $(\mathrm{p}<0.001)$ (3). Çalışmamızda hastalar primer lezyona uygulanan operasyon şekline göre palyatif ve küratif amaçlı olarak analiz edildi. Küratif opere olan hasta grubunda tanı anında erken-lokal ileri evre olup takiplerde metastatik olan ve metastazektomi uygulanan hastalar mevcuttu. Sağkalım süresinin uzun saptanmasinda bu etmenlerin katkis1 olabileceği düşünüldü. Palyatif opere olan 
hastalarda ise opere olmayanlara göre sağkalım süresinin uzun olmasında hastanın performans durumunun daha iyi olması, hastanın sonraki basamakta uygulanan kemoterapi tedavilerinin rolü olduğu düşünüldü. Fakat kemoterapi uygulamalarını kaldıramayacak olan hastalarda ise palyatif cerrahi uygulamalarının hastada sınırlı süre dahi olsa yaşam süresine etkisi olabilmektedir.

KRK'de karaciğer (KC) en sik metastaz bölgesidir. $\mathrm{Bu}$ durum gastrointestinal sistemin venöz drenajının doğrudan KC'e olmasından kaynaklanmaktadır. KRK' li hastaların tan 1 anında $\% 20$ ve takipleri sırasında \% 50'sinde KC metastazı gelişir (4). Bizim hastalarımızda da literatürle uyumlu olarak en sik metastaz yeri $\mathrm{KC}$ idi. $\mathrm{KC}$ metastazlı hastaların sadece \% 10 -20'lik k1smında metastazektomi şansı vardır (5). KC metastazlarının unrezektable olması kötü prognozu gösterir. Kolon kanseri tanılı ve KC'e cerrahi işlem uygulanmış, geniş hasta katılımı (7764 hasta) olan bir çalışmada genç ve yaşlı hastalarda metastazektomi sonuçları rapor edilmiştir. 70 yaş ve üzeri olan 1624 hastanın analizinde 3 yıllık median sağkalım süresi 43 ay olarak bildirilmiştir ve genç hastalar ile kıyaslandığında 3 yıllık hastalıksız sağkalım oranı \%37 olup, iki grup arasında farkl11ık gösterilememiştir (p:0.051) (6). Bizim hastalarımızın \%13,6'sına metastazektomi uygulanmıştı. Uygulanan hastalarda ortanca sağkalım süresine ulaşlamazken, uygulanmayanlarda ise 12 ay idi. Metastazektomi uygulanması yaşam süresini etkileyen bağımsız faktördür.

Metastatik KRK tedavisinde kemoterapi iyi tanımlanmış palyatif tedavi seçeneğidir. Kemoterapi bağımsız olarak yaşam süresi için prediktif belirteçtir. 22 klinik çalışmanın analizinde 70 yaş üzeri 629 hasta analiz edilmiştir (7). Çalışmada 5-FU içeren kemoterapi rejimlerinin genç ve yaşlı hastalarda benzer PFS (5.5 aya karşıı 5.3 ay, $p: 0.01$ ) ve OS (10.8 aya karşın 11.3 ay, p:0.31) sonuçları gösterdiği, ve toksisite açısından gruplar arasında farklılık olmadığ saptanmıştır. Metastatik KRK tedavisinde kullanılan irinotekan ile yapılan bir faz 3 çalışmada, PFS ve OS değerlerinin kronolojik yaştan etkilenmediği, fakat yaşlı hastalarda 34. derece diyare ve nötropeni açısından dikkatli olunması gerektiği rapor edilmiştir (8). 5-FU ve kapesitabine, okzaliplatin eklendiği MRC
FOCUS2 çalışmasında hastaların \% 43'ü yetmiş beş yaş ve üzeri, \% 13'ü ise seksen yaş üzeriydi. $\mathrm{Bu}$ çalışmanın sonucunda, doz redüksiyonu ile tedaviye başlama gibi uygun dizayn ile yaşlı ve frajil hastaların da klinik çalışmalara katılabileceği gösterilmiştir (9). Bu çalışmada 5-FU'ya doz azaltılmış okzaliplatin eklenmesi ile PFS'de anlamlı farkl111k oluşturmadığı (5.8 aya karşın 4.5 ay, p:0.07), 5-FU'nun kapesitabin ile değiştirilmesinin de yaşam kalitesinde yükselme oluşturmadığı ve toksisite riskinde artış gösterdiği saptanmıştır. Yaşlı hastalarda kemoterapi toksisitesini azaltmak için 'stop and go' rejiminin veya 5FU bazlı kemoterapinin idame olarak uygulanmasının daha yararlı olabileceği düşüncesi oluşmuştur. OPTIMOX-1 çalışmasında 76-80 yaş arası hastalarda 'stop and go' rejimi (6 kür FOLFOX-7, sonrasinda 12 kür 5-FU ve takibinde yeniden FOLFOX-7 başlanması) uygulanmış olup progresyona kadar verilmiş olan FOLFOX-4 rejimi ile benzer etkililik ve tolerabilite gösterilmiştir (10).

Yaşlı hastalar yandaş hastalıklar, performans düşüklüğü ve uzun tedavi süreleri nedeni ile palyatif kemoterapi sirasında sikıntı yaşamaktadırlar (3). Yaşlılarda yandaş hastalık insidans1 yüksektir. Bu hastaların genel tıbbi durumlarındaki karmaşıklık, kanserin getirdiği ek sorunlar nedeniyle daha da güç bir hal alır (11). Çalışmamızda hastaların \% 64' ünde en az bir tane olmak üzere yandaş hastalık mevcuttu ve sağkalımı olumsuz etkilemekteydi.

Çalışmamızda hastaların \%27.3'üne kemoterapi uygulaması sirasinda doz redüksiyonu yapılmıştı. Genel olarak hastaların kemoterapi tolerasyonu iyiydi. Fakat çalışmanın retrospektif dizayn edilmesi yan etki bilgilerinde eksikliklere yol açmış olabilir.

Metastatik KRK tedavisinde hedef biyolojik ajanlar geniş yer almaktadır. İlaçlar ile ilgili çalışmalar ve eşliğinde tartışmalar devam etmektedir. Vasküler endotelyal büyüme faktörü (VEGF) inhibisyonu üzerinden etki eden bevasizumabın yaşlı hastalarda kullanımını cesaretlendiren çalışmalar olmasına rağmen 70 yaş ve özellikle 75 yaş üzeri hastalarda kullanımı ile ilgili belirsizlik mevcuttur (12). Yapılan dört randomize çalışmanın analizinde $>65$ yaş hastalarda konvansiyonel kemoterapiye bevasizumab eklenmesinin PFS ve OS'de 
belirgin yararı olduğu saptanmıştır (13). Fakat, ileri yaş hastalarda arteriyal tromboembolik olayların görülme sıklığında artış gözlenmiştir. BRITTE çalışmasında bevasizumab içeren 1 . basamak kemoterapi sonuçlarında PFS açısından yaş grupları arasında farklılık saptanmamış. Fakat ilerleyen yaş ile birlikte OS'de düşüş rapor edilmiştir $(<65$ yaş, 26.0 ay; $65-75$ yaş, 21.1 ay; $75-80$ yaş, 20.3 ay; $\geq$ 80 yaş, 16.2 ay) (14). AVEX, çok merkezli, faz 3 bir çalışma olup ileri yaş hastalarda kapesitabin tedavisine bevasizumabin eklenmesi ile OS'de değişiklik gözlenmezken PFS'de anlamlı artış saptanmıștır (9.1 aya karşın 5.1 ay; $\mathrm{p}<0.01) \quad(15)$. Ziv-aflibercept rekombinant füzyon proteinidir. Hem VEGF ve hem de plasental growth faktörü bağlar ve Vegf trap olarak adlandırılır. VELOUR çalışmasında genel sağkalımda 1,4 aylık yarar gözlenmiştir (13.5 aya karşın 12.1 ay, p:0.003). Alt grup analizde daha önce bevasizumab almamış olan hastalarda sağkalım yararının daha belirgin olduğu gözlenmiştir (16). Merkezimizde yürütülen klinik çalışma nedeni ile üç hasta Ziv-aflibercept/FOLFIRI kombinasyon tedavisi aldı. Hastalarda yan etki olarak diyare, bulant1-kusma, stomatit ve nötropeni gözlendi.

RAS mutasyon durumu anti-epidermal growth faktör (EGFR) tedavilere yanıt için prediktiftir. PRIME ve FIRE-3 çalışmalarında anti-EGFR tedaviler için sadece KRAS kullanılmamas1 NRAS durumunun da bilinmesi gerektiği gösterildi $(17,18)$. Bizim çalışmamızda hastaların \% 41'inde K-RAS durumu bilinmemekteydi. Bir hastada KRAS mutant/ NRAS mutant olmayan, 1 hastada KRAS mutant/ NRAS mutant olarak saptandi. NRAS durumunun bilinme oranının düşük olmasindaki neden testin hastanemiz ve Türkiye koşullarında son zamanlarda uygulanması idi.

Primer tümör lokalizasyonun prognostik etkisi ilk olarak 1990 yılında rapor edilmiştir (19). Arnold ve arkadaşlarının çalışmasında să̆ kolon yerleşimli olan hastalarda sol kolon yerleşimli olanlara göre genel sağkalım ve progresyonsuz sağkalım daha kötü idi (20). Literatür ile uyumlu olarak hastalarımızda sol kolon yerleşimli olanlarda genel sağkalım süresi daha uzundu.

Retrospektif olarak dizayn edilmesi çalışmamızın kısıtlayıcı yönleri idi. $\mathrm{Bu}$ nedenden dolayı hastaların tedavi ilişkili yan etki bilgilerinde ve kapsamlı geriatrik değerlendirme skorlamalarında eksiklikler gözlenmiştir.

\section{SONUÇ}

Kronolojik yaş tedavi planlamasında negatif bir faktör olarak düşünülmemelidir. Tanı ve evreleme sonrasında hastanın kişisel istekleri de gözönüne alınarak multidisipliner yaklaşım ile tedavi seçenekleri uygulanmalıdır. Tedavinin temel taşı olan cerrahi gözardı edilmemelidir. Kombinasyon kemoterapi rejimleri ve hedef tedavilerin uygulanmasindan kaçınılmamalıdır. Karşılaşılabilecek yan etkiler için yakın ve dikkatli takip yapılmalı, gerekli durumlarda destek tedaviler uygulanmalıdır.

\section{Conflict of interest:None}

\section{REFERANSLAR}

1. Tuna S. Kanserli geriatrik hastalarda komorbidite ve klinik değerlendirme. Türk Onkoloji Dergisi 2007;4:192-96.

2. Kristjanson SR, Wyller TB. Introduction.Section 1 in: Schrijvers D, Aopro M, Zakotnik B, Audisio R, Van Haltren H, Hurria A. Esmo Handbook of Cancer in the Senior Patient. First published. London and New York: Informa Health Care.2010:1-7.

3. Ahn HJ, Oh HS, Ahn Y, et al. Prognostic Implications of Primary Tumor Resection in Stage IVB Colorectal Cancer in Elderly Patients. Ann Coloproctol.2014;30 (4):175-81.

4. Jessup JM, McGinnis LS, Steele GD. The National Cancer Data Base. Report on colon cancer. Cancer.1996;78:918-26.

5. Adam R. Chemotherapy and surgery:New perspectives on the treatment of unresectable liver metastasis.Ann Oncol 2003;14:13-16.

6. Adam R, Frilling A, Elias D, et al.Liver resection of colorectal metastases in elderly patients. Br J Surg. 2010;97: 366-76.

7. Folprecht G, Cunningham D, Ross P, et al.Efficacy of 5-fluorouracil-based chemotherapy in elderly patients with metastatic colorectal cancer: a pooled analysis of clinical trials. Ann Oncol. 2004;15:1330-38.

8. Fuchs CS, Moore MR, Harker G, Villa L, Rinaldi D, Hecht JR. Phase III comparison of two irinotecan dosing regimens in second-line therapy of metastatic colorectal cancer. J Clin Oncol. 2003;21:807-14.

9. Seymour MT, Thompson LC, Wasan HS, et al. Chemotherapy options in elderly and frail patients with metastatic colorectal cancer (MRC FOCUS2): an openlabel, randomised factorial trial. Lancet.2011;377:1749-59. 
10. Figer A, Perez-Staub N, Carola E, et al. FOLFOX in patients aged between 76 and 80 years with metastatic colorectal cancer: an exploratory cohort of the OPTIMOX1 study. Cancer. 2007;110:266671.

11. Extermann M, Aapro M, Bernabei R, et al. Use of comprehensive geriatric assessment in older cancer patients: recommendations from the task force on CGA of the International Society of Geriatric Oncology (SIOG). Crit Rev Oncol Hematol. 2005;55:241-52.

12. Hofheinz $R$, Petersen V, Kindler $M$, et al. Bevacizumab in first-line treatment of elderly patients with metastatic colorectal cancer:German community-based observational cohort study results. BMC Cancer.2014,14:761.

13. Cassidy J, Saltz LB, Giantonio BJ, Kabbinavar FF, Hurwitz HI, Rohr UP. Effect of bevacizumab in older patients with metastatic colorectal cancer: pooled analysis of four randomized studies. J Cancer Res Clin Oncol. 2010;136:737-43.

14. Kozloff MF, Berlin J, Flynn PJ, et al. Clinical outcomes in elderly patients with metastatic colorectal cancer receiving bevacizumab and chemotherapy: results from the BRiTE observational cohort study. Oncology.2010;78:32939.

15. Cunningham D, Lang I, Marcuello E, et al.Bevacizumab plus capecitabine versus capecitabine alone in elderly patients with previously untreated metastatic colorectal cancer (AVEX): an open-label, randomised phase 3 trial. Lancet Oncol.2013;14:1077-85.

16. Patel A, Sun W. Ziv-aflibercept in metastatic colorectal cancer. Biologics 2014;8:13-2.

17. Heinemann V, von Weikersthal LF, Decker $T$, Kiani A, Vehling-Kaiser U. FOLFIRI plus cetuximab versus FOLFIRI plus bevacizumab as first-line treatment for patients with metastatic colorectal cancer (FIRE-3): a randomised, openlabel, phase 3 trial. Lancet Oncol. 2014;15(10):1065-75.

18. Douillard JY, Siena S, Cassidy J, Tabernero J, Burkes R. Final results from PRIME: randomized phase III study of panitumumab with FOLFOX4 for first-line treatment of metastatic colorectal cancer. Ann Oncol.2014;25(7):1346-55.

19. Bufill, J.A. Colorectal cancer: evidence for distinct genetic categories based on proximal or distal tumor location. Ann Intern Med.1990;113:779-8.

20. Arnold D, Lueza B, Douillard JY, et al. Prognostic and predictive value of primary tumour side in patients with RAS wild-type metastatic colorectal cancer treated with chemotherapy and EGFR directed antibodies in six randomized trials. Ann Oncol. 2017;28:1713-29. 